\title{
Studies on the recrystalization of nanocrystalline metals
}

\author{
Zofia Lendzion-Bieluń, Marta Gleń \\ Szczecin University of Technology, Institute of Chemical and Environment Engineering, ul. Pułaskiego 10, \\ 72-322 Szczecin, Poland, e-mail: zosi@ps.pl
}

\begin{abstract}
The influence of the promoters such as $\mathrm{CaO}, \mathrm{Al}_{2} \mathrm{O}_{3}$ and $\mathrm{K}_{2} \mathrm{O}$ on the specific surface area of the nanocrystalline cobalt was determined. The recrystalization process of the nanocrystalline cobalt was determined and compared with the examinations conducted on the iron catalyst for ammonia synthesis. The triply promoted nanocrystalline obtained cobalt after the annealing process, has got greater specific surface area than the triply promoted iron.
\end{abstract}

Keywords: nanocrystalline cobalt, recrystalization.

Presented at VII Conference Wasteless Technologies and Waste Management in Chemical Industry and Agriculture, Międzyzdroje, 12 - 15 June, 2007.

\section{INTRODUCTION}

Nanocrystalline transition metals, and among them cobalt, show interesting magnetic, optical and chemical properties which forebode a wide application in different fields i.e. in the catalytic processes. It is well known that the recrystalization process, relevant to the average crystallite size growth and decrease of the specific surface area, causes a decrease in the active surface that consequently leads to a deactivation of the catalyst ${ }^{1}$.

Based on the examinations performed with the iron catalyst for ammonia synthesis, the main phase is nanocrystalline iron, it was claimed that the one-component system aimed to decrease the specific surface area and minimize the surface energy by the surface reconstruction. In the multicomponent systems, due to the wetting process, a two-dimensional structure is created on the surface and its bond energy compensates the surface energy ${ }^{2,3,4}$. Additionally it was claimed that the sintering process of the iron catalyst proceeded at temperatures above $500^{\circ} \mathrm{C}$.

The objective of this research was to determine the influence of temperature and structural promoters on the recrystalization process of nanocrystalline cobalt and compare with the examinations conducted on the iron catalyst for ammonia synthesis.

\section{EXPERIMENTAL}

Nanocrystalline cobalt was obtained by the precipitation of cobalt hydroxide, followed by calcination and reduction. The cobalt hydroxide was precipitated from the cobalt nitrate solution using the $25 \%$ ammonia solution. The obtained deposit was washed with water, filtered and next dried at $70^{\circ} \mathrm{C}$. The next preparation step was the calcinations at $200^{\circ} \mathrm{C}$ for 2 hours. The precursor of nanocrystalline cobalt after the calcinations was reduced under the pure $(99,999 \%)$ hydrogen flow of $20 \mathrm{Ndm}^{3} / \mathrm{h}$. The reduction was carried out in a differential reactor with the thermogravimetric mass measurement. The sample of the precursor of nanocrystalline cobalt of $0,5 \mathrm{~g}$ was placed as a single layer of grains on a platinum basket. Taking into account the single layer of grains in the basket and the conditions of the reaction rate measurements (fixed concentration on the reactor inlet and outlet, a low maxi- mal partial pressure of the reaction product $-\mathrm{H}_{2} \mathrm{O}$ ), the experimental reactor can be considered as a differential one. The first reduction step $\left(\mathrm{Co}_{3} \mathrm{O}_{4}\right.$ is reduced to $\left.\mathrm{CoO}\right)$ was carried out isothermaly at $240^{\circ} \mathrm{C}$. Before each isothermal reduction the sample was annealed in the flow of pure helium $(99,999 \%)$ up to the process temperature.

Then, using the impregnation process, structural promoters aluminum, calcium and potassium oxide were introduced. The nitrate solutions of these elements were used for the impregnation. Drying at the temperature of $150^{\circ} \mathrm{C}$ over 2 hours and the polythermal reduction were the next steps of the process. The reduction process was carried out in the temperature range $25-500^{\circ} \mathrm{C}$, with the heating rate of $2^{\circ} \mathrm{C} / \mathrm{min}$.

To evaluate the recrystallisation process of nanocrystalline cobalt the specific surface area has been determined during the overheating of cobalt under reduction conditions at the temperature of 500 to $700^{\circ} \mathrm{C}$, with a step of $50^{\circ} \mathrm{C}$. The surface area measurement were performed with the nitrogen adsorption/desorption method. Nitrogen adsorption on nanocrystalline cobalt was determined at $-195^{\circ} \mathrm{C}$ and gas desorption at the room temperature. A detailed description of the iron catalyst recrystallization process was reported earlier in the ${ }^{2,3}$.

\section{RESULTS AND DISCUTION}

The specific surface area of $\mathrm{Co}_{3} \mathrm{O}_{4}$ obtained by precipitation, and followed by calcinations at $200^{\circ} \mathrm{C}$ over 2 hours, amounts to $44 \mathrm{~m}^{2} / \mathrm{g}$. The first step of the reduction leads to obtaining the $\mathrm{CoO}$ phase with the specific surface area of $33 \mathrm{~m}^{2} / \mathrm{g}$ and the mean size of crystallites of ca 9 nm.

The chemical composition of the samples after impregnation is presented in Table 1.

Figure 1 shows the reduction degree of the cobalt oxide as a function of polythermal reduction time at the temperature up to $500^{\circ} \mathrm{C}$. The total reduction degree was reached by the sample of pure cobalt oxide (P3).

Addition of the promoters slows down the reduction process and the samples do not reach the total reduction degree.

According to the earlier studies ${ }^{5}$ the increase of the concentration of promoters causes the increase of the $\mathrm{CoO}$ 
Table 1. The content of promoters in the precursor of the nanocrystalline cobalt

\begin{tabular}{|l|c|c|c|}
\hline Sample name & $\begin{array}{c}\mathrm{Al}_{2} \mathrm{O}_{3} \\
{[\text { wt. \%] }}\end{array}$ & $\begin{array}{c}\mathrm{CaO} \\
\text { [wt. \%] }\end{array}$ & $\begin{array}{c}\mathrm{K}_{2} \mathrm{O} \\
\text { [wt. \%] }\end{array}$ \\
\hline P3 & 0.00 & 0.00 & 0.00 \\
PI7 & 3.00 & 0.00 & 0.00 \\
PI8 & 3.00 & 1,60 & 0.00 \\
PI9 & 3.00 & 1,60 & 0.60 \\
\hline
\end{tabular}

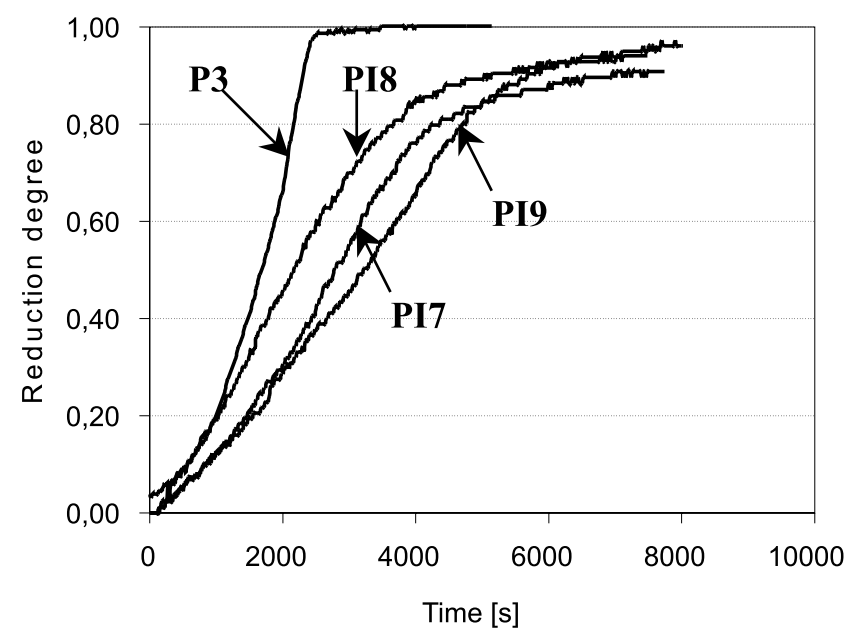

Figure 1. The reduction degree of the cobalt oxide after impregnation as a function of polythermal reduction time (at the temperature range $25-500{ }^{\circ} \mathrm{C}$, with the heating rate of $2^{\circ} \mathrm{C} / \mathrm{min}$ )

mass, which is bound in hardly reducible structures $\mathrm{xCoO} \cdot \mathrm{yMe}_{\mathrm{n}} \mathrm{O}_{\mathrm{m}}$.

Cobalt, obtained by of the oxide phase reduction without structural promoters $(\mathrm{P} 3)$ at $500^{\circ} \mathrm{C}$, has got a relatively small specific surface area ca $2,0 \mathrm{~m}^{2} / \mathrm{g}$. The addition of a small amount of a structural promoter, aluminium oxide $\left(\mathrm{Al}_{2} \mathrm{O}_{3}-3.00 \mathrm{wt} \%\right)$, results in cobalt, obtained in the same way (PI7), demonstrating the specific surface area amounting to $26 \mathrm{~m}^{2} / \mathrm{g}$. The addition of the second promoter, calcium oxide $\left(\mathrm{PI} 8, \mathrm{Al}_{2} \mathrm{O}_{3}-3.00 \mathrm{wt} \%, \mathrm{CaO}\right.$ $-1,6 \mathrm{wt} \%)$, causes an increase of the specific surface area to ca $30 \mathrm{~m}^{2} / \mathrm{g}$. After an addition of the third promoter, potassium oxide (PI9, $\mathrm{Al}_{2} \mathrm{O}_{3}-3.00 \mathrm{wt} \%, \mathrm{CaO}-1,6 \mathrm{wt}$ $\left.\%, \mathrm{~K}_{2} \mathrm{O}-0,6 \mathrm{wt} \%\right)$, a decrease of the specific surface area to ca $25 \mathrm{~m}^{2} / \mathrm{g}$ is observed. A similar effect was observed in the catalyst for the ammonia synthesis where the specific surface area of the two-promoted catalyst, after reduction at the temperature of $500^{\circ} \mathrm{C}$, amounts to $24 \mathrm{~m}^{2} / \mathrm{g}$, whereas of the three-promoted catalyst amounts to ca $12 \mathrm{~m}^{2} / \mathrm{g}$.

The specific surface area $\mathrm{S}$ as a function of the annealing time in a reducing atmosphere $\left(\mathrm{H}_{2}\right)$ of the nanocrystalline cobalt with structural promoters (P19) was shown in Figure 2. At the temperatures $500-$ $700{ }^{\circ} \mathrm{C}$ the specific surface area of the cobalt catalyst decreases with the increase of the reduction temperature. According to the shape of the lines representing the changes of the specific surface area during the reduction, the equilibrium state is reached at each temperature.

The obtained results were interpreted on the basis of the double layer model of the iron catalyst ${ }^{6}$. The basic assumption of this model concerns the equilibrium between the catalyst bulk, surface and the three-dimensional promoter oxides, bonding cobalt crystallites between them. The excess of the surface energy of the system is compensated by the energy of the Co-O bonds on the surface, the

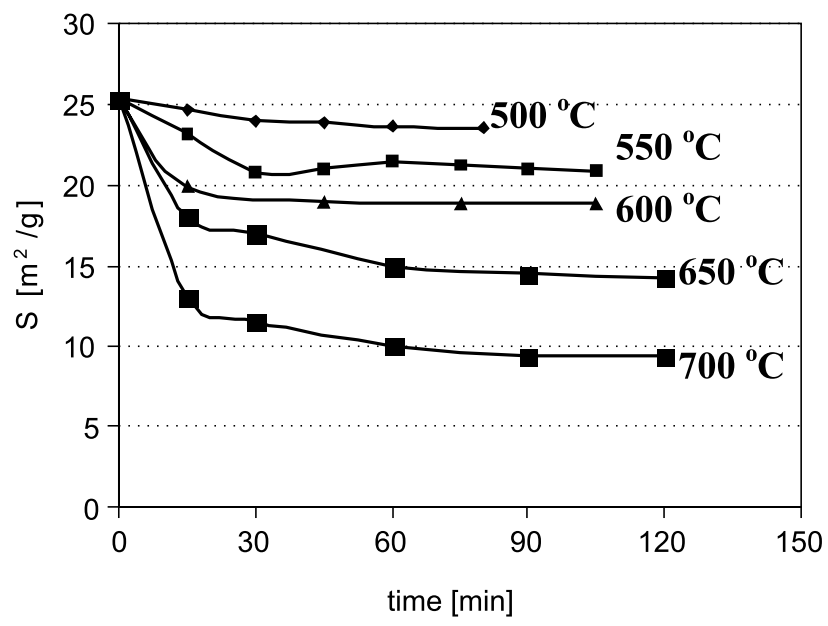

Figure 2. The specific surface area $S$ as a function of the annealing time in a reducing atmosphere of the nanocrystalline cobalt with structural promoters PI9 $\left(\mathrm{Al}_{2} \mathrm{O}_{3}-3,0\right.$ wt \%, $\mathrm{CaO} 1,6$ wt $\%$ and $\mathrm{K}_{2} \mathrm{O} 0,6$ wt $\%$ )

amount of oxygen atoms on the iron surface determines the specific surface area of the catalyst. The specific surface area of the catalyst can be expressed as a ratio of the number of surface cobalt atoms to the number of cobalt atoms in the bulk. The decrease of the catalyst specific surface area, according to the assumptions of the active surface model, takes place after the surface Co-O- bonds cleavage, Fig. 3. This goes with the transition of promoters from the crystallites surface to the three-dimensional structure interior which bonds crystallites.

structure 2D structure $3 \mathrm{D}$

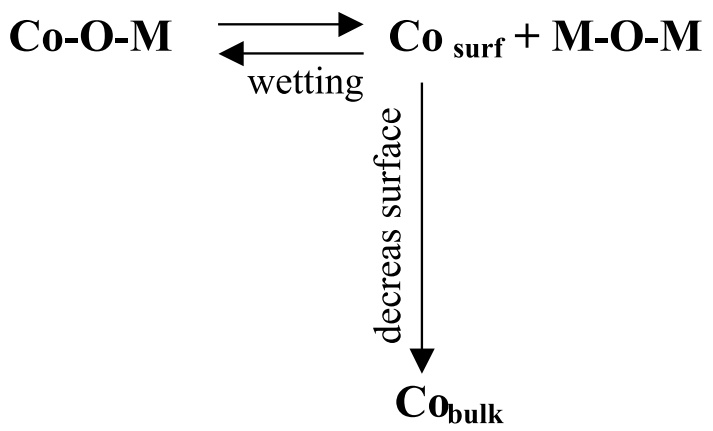

Figure 3. A diagram of the recrystallization and wetting process of the cobalt surface ${ }^{7}$

An equilibrium of the recrystalization process can be described by the following equation : $\mathrm{Co}_{\text {surf }}=\mathrm{Co}_{\text {bulk }}$. The form of the equilibrium constant $\mathrm{k}$ is as follows: $\mathrm{K}=\frac{[\text { Cobulk }]}{\left[\text { Cosurf }_{\text {s }}\right]}$.

The final equilibrium states, characterized by the specific surface area depending on the annealing temperature, for triply (PI9) and for double (PI8) nanocrystalline cobalt promoted were compared with the results for the triply and double promoted iron catalyst, Fig. 4.

On the basis of the data presented in Fig. 4. the free Gibbs enthalpy of the recrystalization process has been determined. The results are presented in Table 2.

The enthalpy of the recrystalization process the triply promoted nanocrystalline cobalt amounts to $\Delta \mathrm{H}_{\mathrm{Co}}=22$ $\mathrm{kJ} / \mathrm{mol}$, whereas for iron amounts to $\Delta \mathrm{H}_{\mathrm{Fe}}=32 \mathrm{~kJ} / \mathrm{mol}$. 


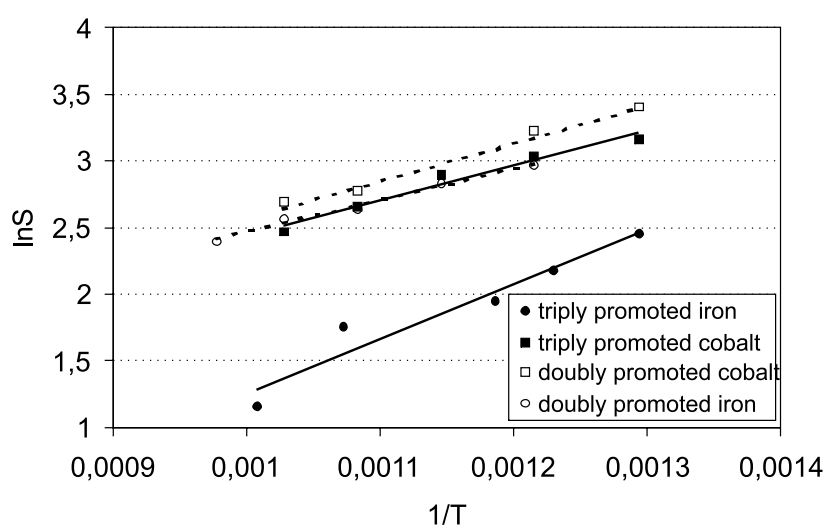

Figure 4. The specific surface area as a function of the annealing time under reducing conditions

Table 2. The values of the recrystalization process enthalpy

\begin{tabular}{|l|c|}
\hline Sample name & $\Delta \mathrm{H}[\mathrm{kJ} / \mathrm{mol}]$ \\
\hline (PI9) triply promoted cobalt & 22 \\
(PI8) doubly promoted cobalt & 24 \\
triply promoted iron & 32 \\
doubly promoted iron & 20 \\
\hline
\end{tabular}

\section{CONCLUSIONS}

It was claimed that the specific surface area of nanocrystalline cobalt during the overheating process, in a short time, reaches the constant value at the defined temperature which says that it reaches the thermodynamic equilibrium state. The obtained triply promoted nanocrystalline cobalt, even after the overheating process, has got the greater specific surface area in comparison with the triply promoted iron.

\section{LITERATURE CITED}

(1) Bartholomew C. H.: Mechanisms of catalyst deactivation, Applied Catalysis A:General, 2001, 212, 17.

(2) Arabczyk W., Jasińska I.: in Proceedeings of the 13th International Congress on Catalysis, Paris, 2004.

(3) Jasińska I., Arabczyk W.: Kinetic studies of the recrystallization process of iron catalyst for ammonia synthesis, Chem. Pap., 2005, 59(6b), 496.

(4) Arabczyk W.: The state of studies on iron catalyst for the ammonia synthesis, Polish Journal of Chemical Technology, 2005, 7. 8.

(5) Lendzion-Bieluń Z., Podsiadły M., Narkiewicz U., Arabczyk W.: Rev. Adv. Mater. Sci., 2006, 12, 145.

(6) Arabczyk W., Narkiewicz U., Moszyński D.: Langmuir, 1999, 15(12), 5785 . 